\title{
ANÁLISE QUALITATIVA E QUANTITATIVA DE ATRIBUTOS VALORATIVOS DE EMPREENDIMENTOS IMOBILIÁRIOS EM PORTO ALEGRE
}

\section{QUALITATIVE AND QUANTATIVE ANALYSIS OF VALUE ATTRIBUTES OF REAL ESTATE ENTERPRISES IN PORTO ALEGRE}

\author{
Fernanda Bolzani Petersen - Porto Alegre - Brasil fernandapetersen@terra.com.br \\ Ângela de Moura Ferreia Danilevicz - Porto Alegre - Brasil angela.danilevicz@pucrs.br
}

\section{Resumo}

Nos grandes centros urbanos, a inovação e o pioneirismo nos empreendimentos imobiliários refletem, de forma sensível, a preocupação do mercado no atendimento de necessidades $e$ anseios da população, especialmente os relacionados com itens de segurança, conforto e lazer das famílias. Por outro lado, a existência de atributos vinculados ao atendimento dessas exigências pessoais, reflete-se também nos custos das unidades residenciais, em razão do que devem ser, adequadamente, analisados e mensurados. De outra parte, uma das etapas mais importantes nos trabalhos de avaliação de imóveis consiste na identificação dos atributos que podem influenciar a formação do valor do bem a avaliar. Tal fato constitui o desafio desta pesquisa, na relação direta com a escassez de estudos aplicados, no âmbito da Engenharia Civil (como gênero) e da Engenharia de Avaliações (como espécie), que buscou e analisou dezenas de atributos que possam influenciar o valor de comercialização dos imóveis, através de experiência viabilizada por pesquisas qualitativas e quantitativas. De tal modo, apreciaram-se as perspectivas dos vários intervenientes do processo: empreendedor, incorporador, investidor, construtor, arquiteto, engenheiro, corretor de imóveis e consumidor, por meio de coleta de informações relativas a imóveis, em lançamento, construção ou acabados, que contemplem ou não os itens estudados.

Palavras-chave: atributos valorativos, pesquisa qualitativa, pesquisa quantitativa, engenharia de avaliações.

\section{Introdução}

Poucos setores no mundo são tão prolíferos na geração de negócios como o imobiliário. Segundo Carvalho (2006), o mercado imobiliário brasileiro vive hoje a fase mais exuberante de sua história. Há expectativas de que o número de negócios deve bater recordes em 2006. A indústria de empreendimentos residenciais e comerciais deve movimentar neste ano cerca de 60 bilhões de reais, valor quase $80 \%$ superior às receitas registradas cinco anos atrás. A abertura de capital das quatro grandes construtoras nacionais nos últimos meses (Rossi Residencial SA, Cyrela Brazil Realty, 
Gafisa, e Company), que captaram juntas mais de 3 bilhões de reais, despertou interesse em investidores estrangeiros. A previsão é que eles invistam 2,3 bilhões de reais em projetos residenciais e comerciais. Associado a esses fatores, o aumento do crédito para o consumidor adquirir o seu bem impulsionou a demanda pela construção de empreendimentos.

Conforme Fonseca (2005), o setor imobiliário é um dos mais dinâmicos de todas as atividades econômicas, sendo a inovação e o pioneirismo a sua marca registrada. Corroborando com este raciocínio, Martins (2006) apresenta que a realização de parcerias com empresas locais permite que a organização passe a entender melhor sobre as necessidades do seu público regional. Dessa maneira, as novidades apresentadas por incorporadores, construtores e imobiliárias são fruto de estudos científicos para melhor entender e atender ao comprador.

Na concepção de um empreendimento, a construtora/ incorporadora irá investigar o públicoalvo, de modo a que isto lhe permita eleger, dentre possíveis atributos, quais os que deverão estar presentes no empreendimento. Esta tomada de decisão pode 'onerar' a obra; entretanto, remunera a construtora/ incorporadora por ocasião da venda, tornando os resultados finais mais satisfatórios. Segundo Fernandez (2001), o processo natural de seleção, pelo mercado, privilegiará as empresas que oferecem o melhor produto (valor agregado) para o mercado.

Desse modo, torna-se importante que os empreendimentos imobiliários sejam planejados de maneira a contemplar os itens valorizados pelos clientes. O presente trabalho visa identificar atributos de destaque e a sua influência na formação do valor de imóveis, levando em consideração o ponto de vista dos intervenientes do processo construtivo, uma vez que o atendimento desses quesitos acaba por refletir no custo final dos empreendimentos.

Uma das etapas mais importantes nos trabalhos de avaliação de imóveis, como procedimento de engenharia, consiste na identificação e priorização desses itens. Estes atributos valorativos compõem a formação do valor de bens imóveis. Dentre eles podem ser citados a qualidade da construção, a existência de área verde, piscina térmica, sala de fitness, quadra poliesportiva, número de vagas na garagem, entre tantos outros possíveis.

Dessa forma, o presente artigo destaca a importância do conhecimento de atributos valorativos, tendo por objetivo a apresentação de uma metodologia para identificação e levantamento da importância desses atributos técnicos, os quais podem influenciar e, via de regra, influenciam, a formação do valor de venda de bens imóveis, cujo fundamento se encontra na Engenharia de Avaliações. 


\section{Fundamentação Teórica}

\subsection{Engenharia de Avaliações}

Dentre os vários métodos avaliatórios constantes da NBR 14653 - Norma Brasileira de Avaliações de Bens, parte 2, destaca-se o método direto comparativo de dados de mercado por ser o mais utilizado e mais recomendado na avaliação de imóveis, permitindo a determinação do valor levando-se em consideração as diferentes tendências e flutuações do mercado imobiliário, freqüentemente diferenciadas de outros ramos da economia (FRAINER, 1993).

Das várias etapas que compõem o laudo avaliatório final, o levantamento de dados de mercado é tarefa fundamental, pois por meio dele vai se constituir a amostra de comparação. A qualidade das informações coletadas na pesquisa é que permitirá identificar as variáveis, características e atributos que serão considerados na avaliação, a partir de critérios adotados pelo avaliador.

Segundo essa metodologia, na estrutura da pesquisa são eleitas as variáveis independentes e a dependente, a qual pretende-se determinar. Sabe-se que a qualidade da amostra e as variáveis estudadas estão diretamente relacionadas à coerência e pertinência dos estudos avaliatórios.

\subsection{Atributos Valorativos}

O presente trabalho trata de atributos de natureza diversa, aqui designados 'valorativos', relacionados com segurança, conforto, localização, padrão e lazer dos empreendimentos e que possam se mostrar importantes na formação do valor de bens imóveis. Assim, apresenta-se uma metodologia para estabelecer e avaliar parâmetros técnicos de sua participação em determinado segmento imobiliário.

Esses atributos variam com a possibilidade financeira do público, como a localização, assim como os critérios de avaliação de prédios corporativos ou empreendimentos imobiliários variam muito de cidade para cidade no Brasil (ou de região para região).

Conforme escreve Dantas (1998), “devido ao número de variáveis influenciantes que teriam algum lugar no modelo explicativo do mercado imobiliário, e a quantidade reduzida de dados que se trabalha na prática, tenta-se na fase de planejamento, na medida do possível, eliminar a presença de algumas variáveis", entendendo-se como tal as menos expressivas quanto à sua importância na formação do valor.

$\mathrm{Na}$ visão dos consumidores, segundo Fonseca (2005), o acesso às ofertas ficou mais fácil, tornando os clientes muito mais informados e exigentes, uma vez que julga o tamanho das peças, a iluminação de ambientes, dentre outros fatores. Diz ainda que o produto não pode pecar em detalhes, porque isso também afeta a decisão de compra do cliente. 


\subsection{Engenharia de Avaliações e o Mercado Imobiliário}

De acordo com Fernandez (2001), o sucesso de um empreendimento imobiliário está relacionado com a correta percepção dos desejos e necessidades do segmento para o qual foi direcionado. Em razão da grande competição entre as construtoras/ incorporadoras, um diferencial qualquer pode ser o objeto da preferência daquele que irá comprar um imóvel.

Segundo Fonseca (2005), "não existe um produto mais aceito pelo consumidor. Existe, sim, um produto adequado para um determinado público-alvo, numa região com demanda e com preço de mercado". A análise das percepções individuais e da atratividade das alternativas de escolha tornam-se, portanto, essenciais, sendo diferenciais no processo de concepção do empreendimento, contribuindo para o seu sucesso, dentro do segmento para o qual foi direcionado.

Além disso, a variação de cálculos e preços no mercado imobiliário torna difícil a distinção entre o imóvel ‘caro' e o 'barato'. O melhor negócio no mercado nem sempre é o que tem o menor valor do metro quadrado, de modo que a composição do preço de um imóvel não está apenas nos valores dispendidos no terreno e na construção. Quando o consumidor adquire um imóvel, ele adquire também um conjunto de fatores agregados, como: acabamentos, infra-estrutura, rua, bairro, proximidades de serviços, escolas e segurança. Assim, na hora da decisão de compra, devem-se analisar alguns fatores que agregam valor à propriedade, para se fazer à distinção entre 'caro' e ‘barato', conforme ITCON (2005).

Conforme González (1997), a literatura de economia urbana, em geral, se refere à existência de um conjunto indissociável de atributos. Assim, os imóveis dotados de muitos atributos serão mais caros. Deste modo, o preço dos imóveis pode ser compreendido como a soma dos produtos das quantidades de cada um destes serviços pelos seus preços implícitos. Inicialmente, não são conhecidas as importâncias relativas, ou as participações no preço de cada um dos atributos. Conhece-se apenas o preço global do imóvel. Cabe então referir a inexistência de trabalhos relativos à análise dos valores dos atributos separadamente, que compõem, em conjunto, o valor total do bem.

Para Leitão (1998), nas etapas de desenvolvimento do produto, devem ser tomadas decisões acerca de parâmetros a serem ponderados pelo arquiteto para a formação do mesmo. Essas escolhas do projetista, quando resultam na correta combinação das exigências do consumidor, podem favorecer a competitividade no mercado imobiliário, e aumentar, substancialmente, o grau de satisfação do cliente. Assim, segundo o mesmo autor, a vantagem competitiva para a empresa promotora do empreendimento pode ocorrer por três diferentes maneiras: diferenciação dos imóveis, pela escolha de um conjunto de atributos que melhor satisfaça aos desejos do consumidor; definição dos atributos mais importantes para um determinado segmento de mercado; melhor entendimento e atendimento das reais necessidades, anseios e desejos dos consumidores em relação 
ao concorrente.

\section{Metodologia}

O presente trabalho de conclusão de curso de graduação buscou desenvolver uma metodologia embasada em pesquisa qualitativa e quantitativa de dados, buscando identificar e quantificar atributos valorativos de empreendimentos imobiliários. Em razão da notável inovação no padrão dos empreendimentos em lançamento e/ ou construção, optou-se pela aplicação de pesquisa para imóveis residenciais, com enfoque dado a apartamentos de três e/ ou quatro dormitórios, situados em bairros nobres de Porto Alegre. Foram escolhidos para análise imóveis para a classe média/ alta, devido à grande variedade de ofertas e opções existentes nesse segmento de mercado, com significativos reflexos nos valores finais.

A metodologia adotada neste artigo irá considerar as aspirações dos diversos intervenientes no processo (clientes e técnicos), por meio de uma amostragem por conveniência, de maneira a identificar os possíveis atributos valorativos quando da escolha ou análise de um imóvel. Para a condução das atividades, a metodologia foi dividida em três etapas complementares: pesquisa qualitativa, pesquisa quantitativa e análise dos resultados.

\subsection{Pesquisa Qualitativa}

O objetivo da etapa qualitativa é investigar, de forma profunda, a opinião de um dado público com relação a um produto, bem ou serviço. Os resultados não são baseados em dados numéricos, mas em depoimentos e informações dos pesquisados. Conforme Giovinazzo (2001), a pesquisa qualitativa é útil para firmar conceitos e objetivos a serem alcançados e dar sugestões sobre variáveis a serem estudadas com maior profundidade.

Algumas possíveis ferramentas para a condução de uma pesquisa qualitativa são: entrevistas, questionários com questões descritivas e focus group. Neste estudo, optou-se pela adoção do Focus Group. Segundo Giovinazzo (2001), o uso dessa ferramenta é particularmente apropriado quando o objetivo é explicar como as pessoas consideram uma experiência, uma idéia, um evento. E, a partir de sua aplicação, torna-se possível a coleta de dados interessantes num curto espaço de tempo, os quais permitem ao pesquisador ou analista a construção de instrumentos, ou referenciais, podendo-se avançar nas investigações.

A pesquisa foi realizada através de um roteiro estruturado de perguntas, aplicado a uma amostra, por conveniência, de players envolvidos com o mercado de Porto Alegre, incluindo representantes do segmento empresarial, profissionais da arquitetura e engenharia, empreendedores, incorporadores, investidores, construtores e corretores de imóveis. Aos profissionais foi solicitado 
que se manifestassem em relação a quais atributos valorizam os imóveis.

\subsection{Pesquisa Quantitativa}

Segundo Ribeiro et al. (2001) a etapa quantitativa permite que sejam realizadas análises numéricas dos dados levantados na etapa qualitativa. Uma pesquisa quantitativa faz uso de instrumentos específicos, capazes de estabelecer relações e causas, levando em conta as quantidades. Antes da aplicação definitiva da pesquisa, o instrumento de coleta de dados deve ser testado e devem ser eliminados todos os possíveis problemas nele existentes.

A condução das atividades teve início no agrupamento por afinidade das informações obtidas na etapa qualitativa. A partir daí estruturou-se um questionário quantitativo para que fossem atribuídos pesos de importância, por parte dos respondentes. Foram entrevistados profissionais e técnicos da área de construção e potenciais compradores de imóveis.

O questionário quantitativo contou, no seu nível primário, com cinco grupos de atributos, listados a seguir.

a) Localização: indicativos quanto à localização do empreendimento e/ ou unidade;

b) Incorporação/ Padrão: atributos relativos ao empreendedor, construtor e projetista e a custos que envolvem o empreendimento, bem como a qualidade geral da obra;

c) Conforto: atributos que contribuem para a qualidade de vida do consumidor, dentro da unidade/ empreendimento;

d) Segurança: itens que conferem segurança ao empreendimento;

e) Lazer: itens de infra-estrutura que proporcionem lazer e entretenimento dentro da área condominial.

A aplicação do questionário quantitativo ocorreu em duas etapas. A descrição do objeto de pesquisa estava associada a um imóvel de três ou quatro dormitórios, padrão classe média/ alta, situado em bairro nobre da cidade de Porto Alegre.

$\mathrm{Na}$ etapa 1 foram realizados três questionamentos distintos. $\mathrm{O}$ primeiro consistiu da realização de avaliação comparativa entre os grupos de atributos, onde o respondente deveria ordenar de 1 a 5 os grupos de atributos, sendo 5 o grupo considerado o mais importante e 1 o menos importante (sem repetição de valores). O segundo e o terceiro questionamento aconteceram através de uma variável dicotômica ( $\operatorname{sim} /$ não) onde era questionada a importância do atributo (sim/não) e se a pessoa estaria disposta a 'pagar a mais' pelo imóvel se aquele atributo estivesse presente ( $\operatorname{sim} /$ não).

Por questões de limitação de espaço, serão detalhados somente os resultados associados à avaliação comparativa dos grupos de atributos. 
Com base nos resultados obtidos foi gerada a Figura 1, onde se encontra representada a ordem de importância entre os grupos de atributos, com base na primeira etapa, descrita acima.

Figura 1 - Grau de importância dos grupos de atributos

\begin{tabular}{|c|c|c|}
\hline Grupo de Atributos & Peso \% & \\
\hline Localização & 27,47 & 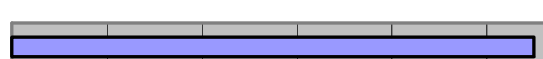 \\
\hline Conforto & 22,71 & 1 \\
\hline Segurança & 20,51 & 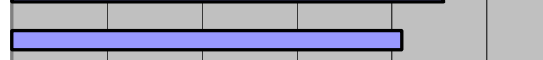 \\
\hline Incorporação / Padrão & 17,58 & 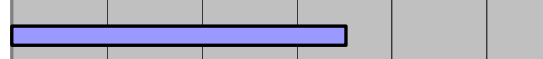 \\
\hline Lazer & 11,73 & 1 \\
\hline
\end{tabular}

Verifica-se que a localização do imóvel ficou em primeiro lugar de importância, seguido de conforto e segurança, respectivamente.

Em relação à importância do fator localização de empreendimentos, quando comparado aos outros atributos, cabe mencionar o apresentado por Fonseca (2005), "[...] uma localização nobre, às vezes, tolera um produto que não seja totalmente adequado. Mas uma localização ruim é fatal para um projeto". Contudo, no que diz respeito à disposição a pagar pelos itens de cada grupo (terceiro questionamento na pesquisa), verificou-se que a maior aceitação está vinculada à segurança, o que se justifica pelo fato deste item ser, atualmente, um dos pontos mais críticos das grandes cidades. $\mathrm{Na}$ etapa 2 também foram conduzidos três tipos de questionamento: o grau de importância de cada atributo dentro do seu grupo; a importância do item (sim/não); e a disposição a pagar a mais pelo item ( $\operatorname{sim} /$ não). No primeiro questionamento, foi solicitado ao entrevistado que atribuísse grau de importância, de 1 a 5, sendo 5 o mais importante e 1 o menos importante, para cada um dos atributos. A diferença é que nesta etapa poderiam ser repetidos os valores da escala de 1 a 5 .

Figura 2 - Priorização dos atributos sob o ponto de vista dos clientes e técnicos 
Grupo de Atributos

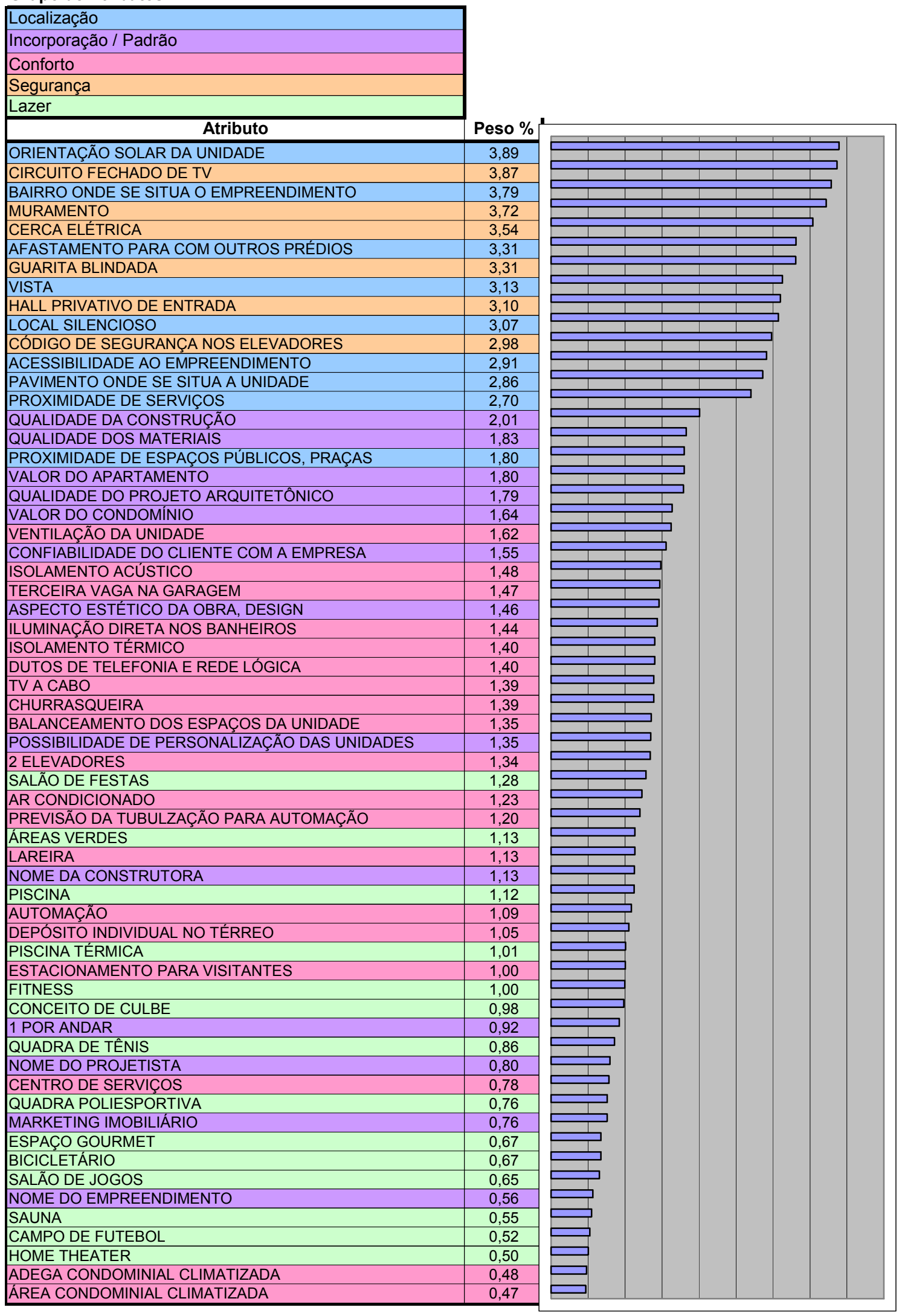

A Figura 2 apresenta os resultados encontrados associados ao grau de importância de cada 
atributo.Na avaliação global, encontra-se em primeiro lugar a orientação solar na unidade (grupo localização), seguido de circuito fechado de TV (grupo segurança); bairro onde se situa o empreendimento (grupo localização); muramento (grupo segurança); e cerca elétrica (grupo segurança). Verifica-se um forte destaque para os grupos de atributos: localização e segurança. A seguir, encontra-se uma análise por grupo de atributo.

Em relação ao grupo Localização, as preferências dos entrevistados se voltaram para a orientação solar da unidade e bairro onde se localiza o empreendimento, com 3,89\% e 3,79\% de aceitação, respectivamente. O destaque da orientação solar, ao ser analisada juntamente com outros atributos, pode ser explicado em função do clima subtropical desta cidade e grande variação de temperatura ao longo de um mesmo dia, ao que se pode acrescentar o fato de ter-se um inverno frio e úmido e um verão com calor intenso na cidade em análise.

Em relação ao grupo Incorporação/ Padrão obteve destaque a qualidade da construção, a qualidade dos materiais utilizados (visando menor manutenção futura), o valor do apartamento e a qualidade do projeto arquitetônica, representada por 2,01\%,1,83\%,1,80\% e 1,79\% de aceitação, respectivamente. Cabe referir ainda que a confiabilidade do cliente em relação à empresa, nome da construtora e possibilidade de personalização das peças obtiveram altos conceitos.

Em relação ao grupo Conforto predominaram preferências de atributos relacionados à ventilação da unidade, com 1,62\%, isolamento acústico, com 1,48\%, e térmico, com 1,40\% e terceira vaga na garagem com $1,47 \%$. Contudo, no questionamento associado à disposição a pagar mais em função do atributo, destacou-se o item relativo à terceira vaga na garagem. Por outro lado, entende-se que as menores preferências em atributos considerados nobres e inovadores, tais como, adega condominial climatizada e área condominial climatizada, respectivamente podem ser atribuídas a questão cultural, ao aumento refletido no custo das unidades, o que caracteriza um padrão superior ao estudado.

Em relação ao grupo Segurança, as preferências se voltaram para a existência de circuito fechado de TV, com 3,87\%, muramento, com 3,72\%, cerca elétrica, com 3,54\% e guarita blindada com 3,31\%. Observa-se a alta percentagem de importância associada aos atributos de segurança, verificando-se que, todos os itens que compõem o grupo ficaram priorizados entre os onze principais atributos a estarem presentes em uma construção. Tal fato sugere que as pessoas valorizam, com grande destaque, a presença dos itens relativos à segurança.

No grupo Lazer, destaca-se a presença de salão de festas, que é um item que satisfaz às diferentes faixas etárias e permite conciliar seu uso com a segurança antes comentada, tendo recebido a preferência de 1,28\%. Após, destacaram-se as áreas verdes, com 1,13\% e piscina com $1,12 \%$ (térmica com 1,01\%) e fitness com 1,00\%. Contudo, cabe referir que o conceito atribuído ao item 'espaço gourmet' (salão de festas com um novo complemento), também foi destacado, por ser 
uma nova opção de lazer, estimulando a convivência social aos compradores, especialmente quando não dispõem deste espaço na sua unidade. Tal atributo também foi apontado na revista ImóvelClass (2005).

Os resultados gerais, mostrados anteriormente, expõem que os atributos de maior importância não são, à primeira vista, os inovadores no mercado. Todavia, acredita-se que estes itens encontram-se em crescente aceitação, de modo que seus conceitos estão sendo aperfeiçoados e absorvidos pelo consumidor, cada vez mais exigente, ciente dos avanços e da competitividade do meio imobiliário.

\section{Conclusões}

O presente trabalho procurou desenvolver um modelo visando à identificação de atributos valorativos que possam influenciar a formação do valor de comercialização dos imóveis, a partir de experiência viabilizada por pesquisas qualitativas e quantitativas.

Visando atingir os objetivos propostos para este estudo, adotou-se um modelo de pesquisa que incluiu procedimentos de desenvolvimento e aplicação de uma metodologia, e de sua validação, através da verificação da consistência dos resultados obtidos.

A avaliação de imóveis, propriamente dita, não foi objeto do presente artigo, mas sim a formulação de critérios práticos para sua aplicação, estimativa de valores e tomada de decisões sobre os itens valorativos passíveis de inclusão num determinado empreendimento.

A adoção de um modelo abarcando um método qualitativo precedendo a um quantitativo, facilitou o processo de pesquisa, tornando possível a identificação de atributos valorativos do ponto de vista do mercado. Isto ocorreu através da apreciação das perspectivas dos vários intervenientes do processo: empreendedor, incorporador, investidor, construtor, arquiteto, engenheiro, corretor de imóveis e consumidor em relação a imóveis em lançamento, construção ou acabados. Foi realizada por meio de uma amostragem por conveniência.

Em paralelo, dentre os benefícios do uso da metodologia aqui adotada, destaca-se a vantagem competitiva para os agentes do mercado, pela diferenciação dos imóveis por meio da escolha de um conjunto de atributos que melhor satisfaça aos desejos do cliente; pela definição dos atributos mais importantes para um determinado segmento de mercado; e pelo melhor entendimento e atendimento de diferentes opções, anseios e desejos do consumidor.

Dentre os resultados obtidos junto ao grupo onde foi conduzida de pesquisa, pode-se identificar uma forte influência dos grupos de atributos localização e segurança. Quando analisado os atributos individualmente verificou-se, para o grupo pesquisado, uma forte relevância dos itens associados ao grupo segurança, o que acaba por refletir a preocupação premente existente em grandes centros urbanos. Isso se justifica à medida que todos os itens que compõem o grupo 
segurança ficaram localizados entre os onze primeiros colocados, em importância.

Assim, acredita-se que a metodologia pode contribuir para o desenvolvimento de itens valorativos de apoio à Engenharia de Avaliações, quando da avaliação de empreendimentos enquadrados no segmento adotado.

\title{
Referências
}

DANTAS, Rubens Alves. Engenharia de Avaliações: uma introdução à metodologia científica. São Paulo: PINI, 1998.

Denise Carvalho. A explosão imobiliária: As razões que fazem o mercado de imóveis viver um momento exuberante - e as dificuldades que podem atrapalhar o crescimento. Revista Exame. n.9, maio, 2006.

ESPAÇO Gourmet: um novo conceito de lazer. ImóvelClass. Porto Alegre, ano 1, n.8, p.16, 2005.

FERNANDEZ, João Alberto da Costa Ganzo. Estruturação de Estudos de Viabilidade de Mercado Para Empreendimentos Habitacionais. IN: II SEMINÁRIO INTERNACIONAL DA LARES - LATIN AMERICAN REAL ESTATE SOCIETY. Santa Catarina: set. 2001.

FRAINER, José Irany et al. Avaliações de Bens Por Estatística Inferencial e Regressões Múltiplas: teoria e aplicações. 2.ed. Porto Alegre: 1993.

GIOvinaZZO, Renata A. Focus Group em Pesquisa Qualitativa. Artigo, Fundação Escola de Comércio Álvares Penteado FECAP, 2001.p.1. Disponível em: <http://www.fecap.br/adm_online/art24/renata2.htm>. Acesso em: 10 set. 2005.

GONZÁLEZ, Marco Aurélio Stumpf. Noções sobre o Conceito de Valor no Mercado Imobiliário.In: IX CONGRESSO BRASILEIRO DE ENGENHARIA DE AVALIAÇÕES E PERÍCIAS - IX COBREAP. São Paulo, 1997.

ITCON, Inteligência e Tecnologia de Consumo, Inteligência Imobiliária. Pioneirismo Sempre. Disponível em: $<\mathrm{http}$ ://www.itcon.br/CRM/gerenciamento/fluxo/ BOLETIM/entr_14.htm>. Acesso em: 08 nov. 2005.

LEITÃo, Elenara Stein. Análise do Comportamento de Compra do Consumidor de Imóveis Residenciais, Estudo de Caso: Apartamentos Novos de 2 e 3 dormitórios. Dissertação de Pós Graduação em Engenharia de Produção. Universidade Federal do Rio Grande do Sul. Porto Alegre, 1998.

NBR 14653. Norma Brasileira de Avaliação de Bens. Parte 2 - Avaliação de Bens Imóveis.

NOTÍCIAS ROSSI. 2005, ano de expansão na Rossi Porto Alegre. Rossi. Ano 2. nov/dez 2005 / jan2006.

RIBEIRO, José Luis Duarte; ECHEVESTE, Márcia Elisa Soares; DANILEVICZ, Ângela de Moura Ferreira. A utilização do QFD na otimização de produtos, processos e serviços. Porto Alegre: FEEng / UFRGS, 2001.

USP Cria sistema de classificação de edifícios comerciais. Conselho em Revista. CREA-RS Maio 2006.

\begin{abstract}
In major urban centers, the innovation and pioneer spirit in real estate enterprises reflect, in a sensible way, the concern of the market in the attending of the needs and desires of the population, especially in regards to the security, comfort and leisure of families. On the other hand, the existence of these entailed attributes in attending to these personal requirements is also reflected in the costs of the residential units, in that they must be adequately analyzed and estimated. In addition, one of the most important stages in the work of real estate appraisal is the identification of
\end{abstract}


those attributes that can influence the formation of the value of the property being appraised. Such facts constitute the challenge of this research, in direct relation to the scarcity of applied studies in the scope of Civil Engineering, as such, and of the Engineering of Evaluations, as a field, which searched and analyzed dozens of attributes that could influence the value of the commercialization of property, by experience made feasible through qualitative and quantitative research. In any case, the perspectives of various professionals involved in this process have been evaluated: entrepreneur, incorporator, investor, builder, architect, engineer, real estate broker and consumer, by means of collecting information relative to properties that are in start-up, in construction, or completed, that are related to or not the material studied.

Key-words: value attributes, qualitative research, quantitative research, engineering of evaluations.

Recebido para publicação em: 15/10/2006

Aceito para publicação em: 01/12/2006 